\title{
Prediction of extreme floods based on CMIP5 climate models: a case study in the Beijiang River basin, South China
}

\author{
C. H. Wu ${ }^{1}$, G. R. Huang ${ }^{1,2}$, and H. J. Yu ${ }^{1}$ \\ ${ }^{1}$ School of Civil Engineering and Transportation, South China University of Technology, Guangzhou 510640, China \\ ${ }^{2}$ State Key Laboratory of Subtropical Building Science, South China University of Technology, Guangzhou 510640, China \\ Correspondence to: G. R. Huang (huanggr@ scut.edu.cn)
}

Received: 4 August 2014 - Published in Hydrol. Earth Syst. Sci. Discuss.: 13 August 2014

Revised: 23 January 2015 - Accepted: 24 February 2015 - Published: 13 March 2015

\begin{abstract}
The occurrence of climate warming is unequivocal, and is expected to be experienced through increases in the magnitude and frequency of extreme events, including flooding. This paper presents an analysis of the implications of climate change on the future flood hazard in the Beijiang River basin in South China, using a variable infiltration capacity (VIC) model. Uncertainty is considered by employing five global climate models (GCMs), three emission scenarios (representative concentration pathway (RCP) 2.6, RCP4.5, and RCP8.5), 10 downscaling simulations for each emission scenario, and two stages of future periods (2020-2050, 2050-2080). Credibility of the projected changes in floods is described using an uncertainty expression approach, as recommended by the Fifth Assessment Report (AR5) of the Intergovernmental Panel on Climate Change (IPCC). The results suggest that the VIC model shows a good performance in simulating extreme floods, with a daily runoff NashSutcliffe efficiency coefficient (NSE) of 0.91. The GCMs and emission scenarios are a large source of uncertainty in predictions of future floods over the study region, although the overall uncertainty range for changes in historical extreme precipitation and flood magnitudes are well represented by the five GCMs. During the periods 2020-2050 and 20502080, annual maximum 1-day discharges (AMX1d) and annual maximum 7-day flood volumes (AMX7fv) are expected to show very similar trends, with the largest possibility of increasing trends occurring under the RCP2.6 scenario, and the smallest possibility of increasing trends under the RCP4.5 scenario. The projected ranges of AMX1d and AMX7fv show relatively large variability under different future scenarios in the five GCMs, but most project an increase during
\end{abstract}

the two future periods (relative to the baseline period 19702000).

\section{Introduction}

Recent research indicates that extreme precipitation is very likely (greater than $90 \%$ probability) to become more intense and more frequent over most of the mid-latitude land masses and wet tropical regions (IPCC, 2013). Increases in extreme precipitation are expected to trigger floods, and the associated impacts will cause probable loss of life and economic damage. It is therefore extremely important to gain an understanding of the projected changes in extreme flood events under climate change.

The most useful tool for investigating the impacts of climate change on floods is a hydrological model driven by outputs from global climate models (GCMs). GCMs are considered to be the most essential and feasible tools for use in supplying useful climate information on global or large scales. However, GCMs generate outputs at a relatively coarse grid scale (of a few hundred kilometres), and therefore their outputs cannot be directly used in climate impact studies at a catchment scale (Sachindra et al., 2014a). Downscaling techniques (e.g. dynamical downscaling and statistical downscaling) are therefore normally used to link coarse resolution GCM outputs with catchment-scale climatic variables (Sachindra et al., 2014b). Dynamical downscaling is performed through regional climate models (RCMs) or limitedarea models (LAMs) (Fowler et al., 2007), whereas statistical downscaling defines the empirical relationships between large-scale variable fields (e.g. climate model outputs) 
and local-scale surface conditions, and translates large-scale GCM outputs onto a finer resolution (Fowler et al., 2007; Tisseuil et al., 2010). Because of the lower computational requirement of statistical downscaling in comparison with those required of dynamical downscaling, it has been widely used in climate-impact-related research work (Sachindra et al., 2014a, b; Tisseuil et al., 2010). However, despite the increase in resolution, downscaling simulation results (e.g. $\mathrm{RCM}$ ) often remain too biased to be used directly in impact models such as hydrological models (Bennett et al., 2014). Therefore, to obtain a realistic output for hydrological simulations forced by future climate, certain statistical bias correction methodologies that involve particular forms of transfer function derived from cumulative distribution functions of observations and model simulations have been developed to produce corrected GCM/RCM simulations (e.g. Bennett et al., 2014; Li et al., 2010). Based on the data provided by GCMs, numerous studies have investigated the effects of climate change on regional floods over the world, including in Europe (Feyen et al., 2012), Germany (Huang et al., 2013), Bangladesh (Mirza et al., 2003), Britain (Kay and Jones, 2012), and China (e.g. Liu et al., 2013; Wu et al., 2014b; Xiao et al., 2013; Xu et al., 2013).

In southern China, there has been a proven increase in the frequency of flood occurrence since the 1980s, particularly in the Beijiang River basin, a northeastern tributary of the Zhujiang River (Wu et al., 2013). To our knowledge, only two studies have previously investigated the effects of climate change on extreme floods over the Beijiang River basin (Wu et al., 2014b; Xiao et al., 2013). Furthermore, a large uncertainty is apparent in the projected values of these studies. It is well known that a multitude of sources of uncertainty are involved in analysis of the impact of climate change, including GCM structure, downscaling from GCMs, emission scenarios, and the hydrological models used and their parameters (Chen et al., 2011; Kay et al., 2009; Liu et al., 2013). Among these, GCM structure uncertainty is likely to be the largest source of uncertainty in relation to the hydrological impacts of climate change (Kay et al., 2009; Prudhomme and Davies, 2009). It is therefore necessary to perform additional comparative analyses on the prediction of future floods over the Beijiang River basin to lower the uncertainty of future climate projections.

As a case study, we use a typical high-risk flooding area of the Beijiang River basin, and aim to explore the response of floods to climate change as derived from the CMIP5 climate models, using a large-scale semi-distributed hydrological model. However, this study differs from previous studies, as it focuses on a comparison of the different GCMs and different climate change scenarios using different stages of the future period. In addition, to highlight the uncertainty of the results, this study uses a new approach in uncertainty expression to describe the credibility of projected changes in floods.

\section{Data and methodology}

\subsection{Study area}

The study area called the Feilaixia catchment is located in the upstream of the Beijiang River (Fig. 1). Feilaixia catchment has a drainage area of approximately $34097 \mathrm{~km}^{2}$ and accounts for $73 \%$ of the Beijiang River basin. It consists of four main tributaries, the Wujiang River, Zhenjiang River, Lianjiang River, and Wengjiang River (Fig. 1). The Hengshi hydrologic station, located at the outlet of the basin, is the discharge station of the Feilaixia catchment (Fig. 1). The region is an important water source for Guangdong province, one of the most developed areas of China. The climate of the region is warm, wet tropical to subtropical, and precipitation during the flood season (April to September) accounts for $70-80 \%$ of the annual precipitation. Due to climate warming, extreme rainfall events are recently occurring more frequently in the Feilaixia catchment (Wu et al., 2014a), which leads to more intense and frequent flooding (e.g. the large floods in June and August 1994, June 1998, June 2005, and July 2006), causing extensive inundations and severe flood damage. This is a serious threat to the flood control safety of Guangzhou city (one of the largest cities in South China) and other areas located in the downstream of the Beijiang basin. For example, the study region experienced the worst flood of the twentieth century in 1994, affecting two million people, and leading to the loss of RMB 3.2 billion (Wong and Zhao, 2001). It is therefore imperative to understand the projected changes in flood risk of this basin.

\subsection{Data sets}

Data used in this study include digital elevation model (DEM), vegetation cover, soil properties, and observed hydro-meteorological data. The DEM (at a resolution of $90 \mathrm{~m}$ ) was derived from the International Scientific \& Technical Data Mirror Site, Computer Network Information Center, Chinese Academy of Sciences. Vegetation coverage data sets were collected from the University of Maryland, and provide information on global land classification at a $1 \mathrm{~km}$ resolution (Hansen et al., 2000). The classification of soil texture at a resolution of $1 \mathrm{~km}$ based on the Harmonized World Soil Database (HWSD) was provided by the Food and Agriculture Organization of the United Nations and the International Institute for Applied Systems Analysis.

Daily hydrological data as recorded at 27 rainfall stations and 1 discharge station (Fig. 1) were provided by the Hydrology Bureau of Guangdong Province, China. Daily maximum and minimum temperature data from four stations were provided by Meteorological Data Sharing Service System, National Meteorological Information Center, China Meteorological Administration (http://cdc.cma.gov.cn/home.do). The data sets from all the stations spanned over the period from 1969 to 2011. 


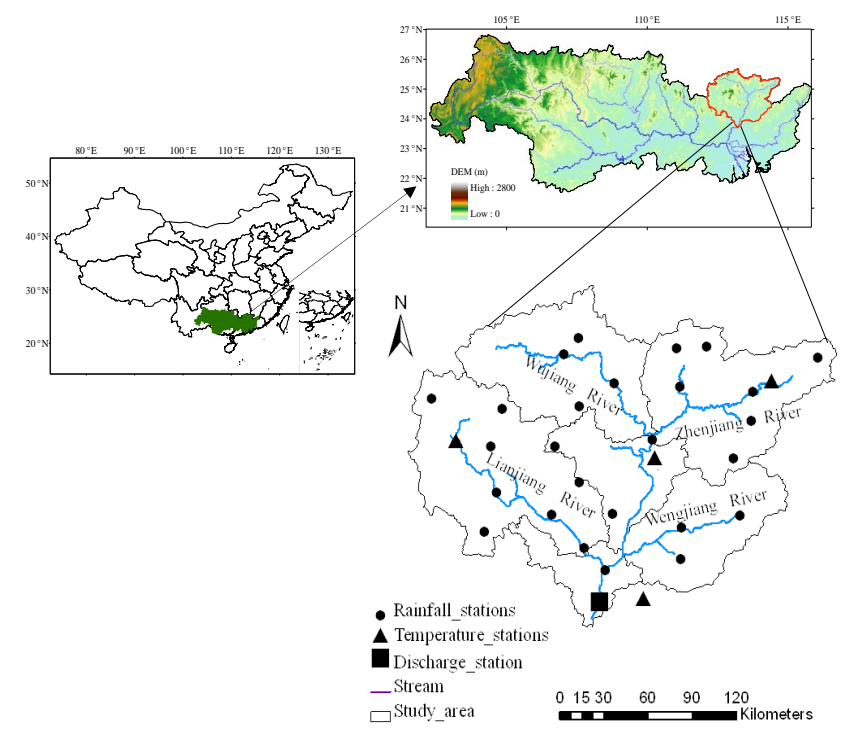

Figure 1. Map showing the location of study catchment.

\subsection{CMIP5 climate models}

CMIP5 is the Coupled Model Intercomparison Project Phase 5 , which provides a framework for coordinated climate change experiments for the next several years and includes simulations for assessment in the AR5 as well as for other assessment reports that extend beyond the AR5 (Taylor et al., 2012). Relative to earlier phases, CMIP5 focuses on a set of experiments that include higher spatial resolution models, improved model physics, and a richer set of output fields (Gulizia and Camilloni, 2015; Taylor et al., 2012). Additionally, the CMIP5 climate change projections are driven by new climate scenarios that use a time series of emissions and concentrations from the representative concentration pathways (RCPs) described in Moss et al. (2010). Accordingly, GCMs provided by the CMIP5 have been widely used in the assessment of climate change (Gulizia and Camilloni, 2015; Pierce et al., 2013; Smith et al., 2013).

When using multiple GCMs to assess future climate change, the underlying assumption is that different models provide statistically independent information. In fact, models usually share physical parameterization schemes, and at times, even large parts of the same code (Pincus et al., 2008), which could lead to similar weaknesses among the models. Pennell and Reichler (2011) evaluated 24 state-of-theart models of the CMIP3 and their ability to simulate broad aspects of twentieth-century climate, and found that the effective number of models (the amount of statistically independent information in the simulations) was significantly less than the actual number of models. Xiao et al. (2013) applied the hierarchical cluster analysis to analyse the precipitation simulation similarity of 47 CMIP5 GCMs over the Zhujiang River basin, and suggested that the 47 GCMs can be classified into five types.
According to Xiao et al. (2013), five CMIP5 GCMs (i.e. BCC-CSM1.1, CanESM2, CSIRO-Mk3.6.0, GISS-E2$\mathrm{R}$, and MPI-ESM-LR), which are independent from each other and have a good performance in current climate simulation for the Zhujiang River basin, were used in this study. The GCMs data (precipitation and temperature) used include (1) an historical simulation for the period 1970-2000 and (2) three new scenarios (RCP2.6, RCP4.5, and RCP8.5) for two different future periods (2020-2050 and 2050-2080).

To generate local climate conditions (e. g. temperature and precipitation) from GCMs, a simple statistical downscaling method was performed as follows. First, the model data and observed station data were interpolated to $0.25^{\circ}$ resolution using bilinear interpolation. Second, the bias between the monthly precipitation and temperature of the observed and GCM output data was corrected using a quantile-based mapping method ( $\mathrm{Li}$ et al., 2010) to reduce system errors in GCM simulations. Finally, a stochastic weather generation method was employed to temporally disaggregate the monthly corrected climate projections into the daily weather forcings required by the hydrological model. To consider the range of variability that this randomness could induce, multiple downscaling simulations were performed for each emissions scenario (Raff et al., 2009). The simulation set size of this study was arbitrarily set to 10 simulations (i.e. 10 downscaling samples).

\subsection{Methodology}

Variable infiltration capacity (VIC) model developed by Liang et al. (1994) is a semi-distributed hydrological model based on a spatial distribution grid. It can simulate the physical exchange of water and energy among the atmosphere, soil and vegetation in a surface vegetation-atmospheric transfer scheme. Further detailed information relating to the VIC can be obtained from University of Washington's website (www.hydro.washington.edu/Lettenmaier/Models/VIC/ index.shtml). As a typical land surface hydrological model, the VIC model has been successfully applied to assess the impact of climate change on hydrology over the Zhujiang River basin (Wang et al., 2012; Wu et al., 2014b; Xiao et al., 2013). In this study, the model VIC 4.1.2b is used to simulate only the water balance, and is run over a regional domain consisting of 69 grid points at a spatial resolution of $0.25^{\circ} \times 0.25^{\circ}$. Meanwhile, the Dag Lohmann model (Nijssen et al., 1997), a routing model, is used for transporting the grid cell surface runoff and baseflow produced by the VIC model within each grid cell to the outlet of that grid cell and then into the river system.

The Mann-Kendall trend test (Mann, 1945; Kendall, 1975) is a nonparametric method to detect the significance of monotonic trends in hydrometeorological series. In this study, we apply the Mann-Kendall method to detect statistical significance of trends in future streamflow series as projected by GCMs. Here, two styles of trends tested are consid- 
ered: trends tested without considering a level of significance and statistically significant trends at the 0.1 level. In addition, the Sen (1968) nonparametric trend slope estimator was used to estimate the trends magnitude in discharge.

The qualifier of likelihood, which provides calibrated language for describing quantified uncertainty, can be used to express a probabilistic estimate of the occurrence of a single event or of an outcome (IPCC, 2013). In this study, a total of 50 simulations for each projection of five GCMs were considered as a whole, and then likelihood terms associated with outcomes were defined as follows (IPCC, 2013): very likely: 90-100 \%; likely: 66-90\%; more likely than not: 50-66\%; about as likely as not: $33-50 \%$; unlikely: $10-33 \%$; very unlikely: 0-10\%.

We also use the qualifier very likely when, for example, the percentage of samples for one emission scenario shows increasing or decreasing trends of up to $90 \%$, we conclude that this trend (either increasing or decreasing) is very likely to occur.

\section{Results and analysis}

\subsection{VIC Model validation}

Observed forcing data required by VIC model were generated based on 27 rainfall stations with daily precipitation data, and four temperature stations with daily maximum and minimum temperature data. The recorded data series was divided into two periods: the period 1969-1990 for model calibration and the period 1991-1999 for model validation. The efficacy of the simulation results was evaluated using the Nash-Sutcliffe efficiency coefficient (NSE) and relative error (RE). Simulated and observed daily discharge and maximum 1(7)-day runoff depths at the Hengshi hydrologic station are illustrated in Fig. 2.

As shown in Fig. 2a, the values of the NSE for the calibration and validation stages are 0.88 and 0.91 , respectively, while the values of the RE are 11.88 and $3.67 \%$, respectively. The VIC model is accurate in simulating daily streamflow, with a high simulation precision of the flood peak in the flood season. In addition, VIC is also successful at simulating maximum 1-day and 7-day runoff depths, with high correlation coefficients above 0.95 (Fig. $2 b$ and c). These results indicate that the model has a good performance in simulating both daily streamflow and extreme floods in the selected catchment, and can therefore be used to estimate the potential impacts of climate change on floods.

\subsection{Comparison of GCM simulations with observations}

To assess the performance of the downscaling outputs from GCMs in simulating extreme precipitation, we compared the empirical cumulative distribution functions (ECDFs) of downscaled annual maximum 1-day and 7-day precipitation (AMX1p and AMX7p, respectively) against the corre-
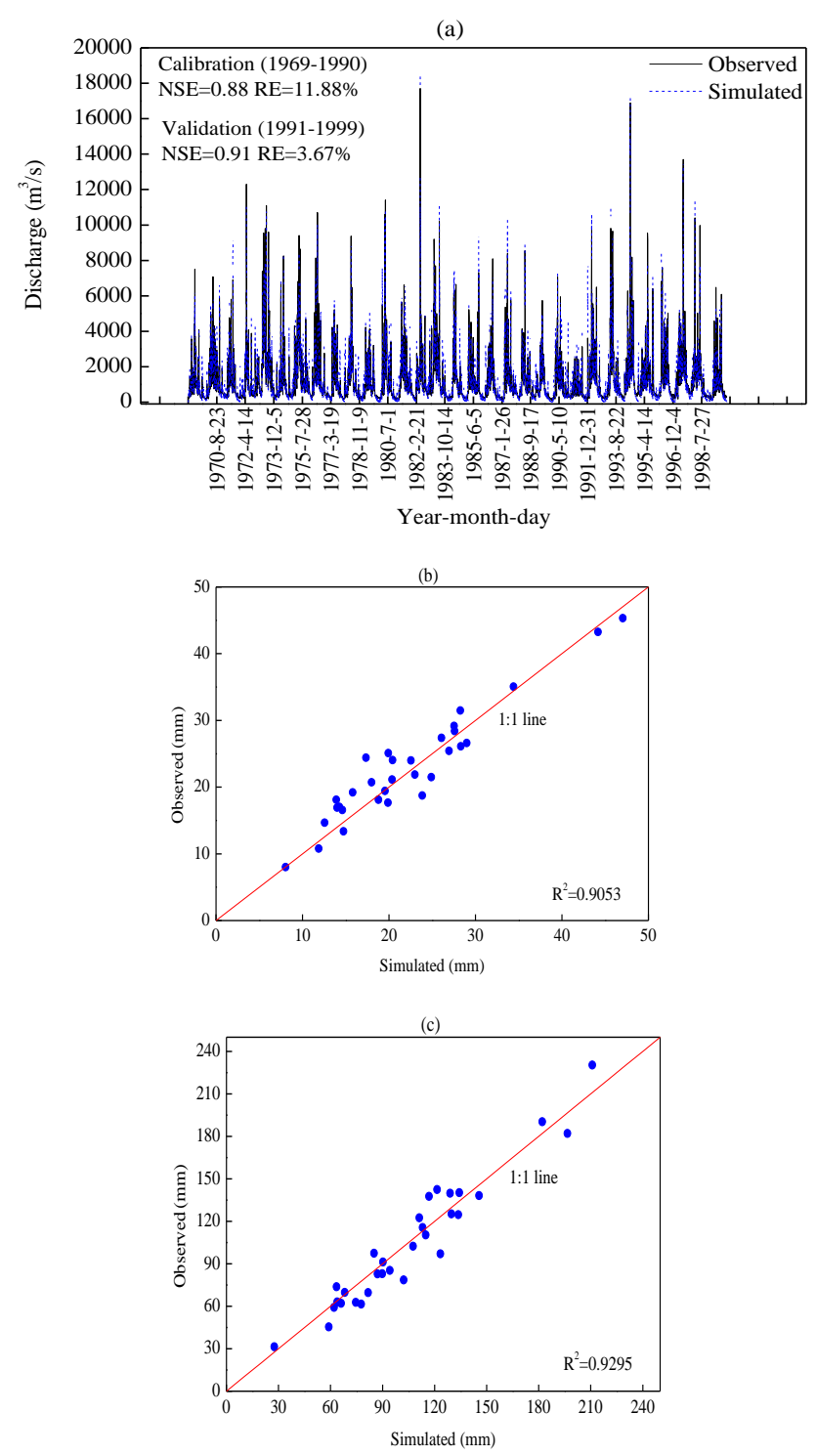

Figure 2. Comparison of the simulated and observed runoff at the Hengshi hydrologic station during the period 1969-1999. (a) A comparison of simulated and observed discharges, (b) a comparison of simulated and observed maximum 1-day runoff depth, and (c) a comparison of simulated and observed maximum 7-day runoff depth.

sponding observations (Fig. 3a and b). The ECDFs of the 10 simulations for each GCM are able to encompass a relatively wide distribution of AMX1p and AMX7p. In terms of the five models, BCC-CSM1.1 and MPI-ESM-LR perform better than the others, but there are relatively large differences between the performances of all the models. For example, CanESM2 underestimates AMX1p for nonexceedance probabilities up to approximately 0.8 , and underestimates AMX7p for non-exceedance probabilities up to approximately 1.0. In addition, some models have a tendency to overestimate maximum values. For example in the case 
(a)
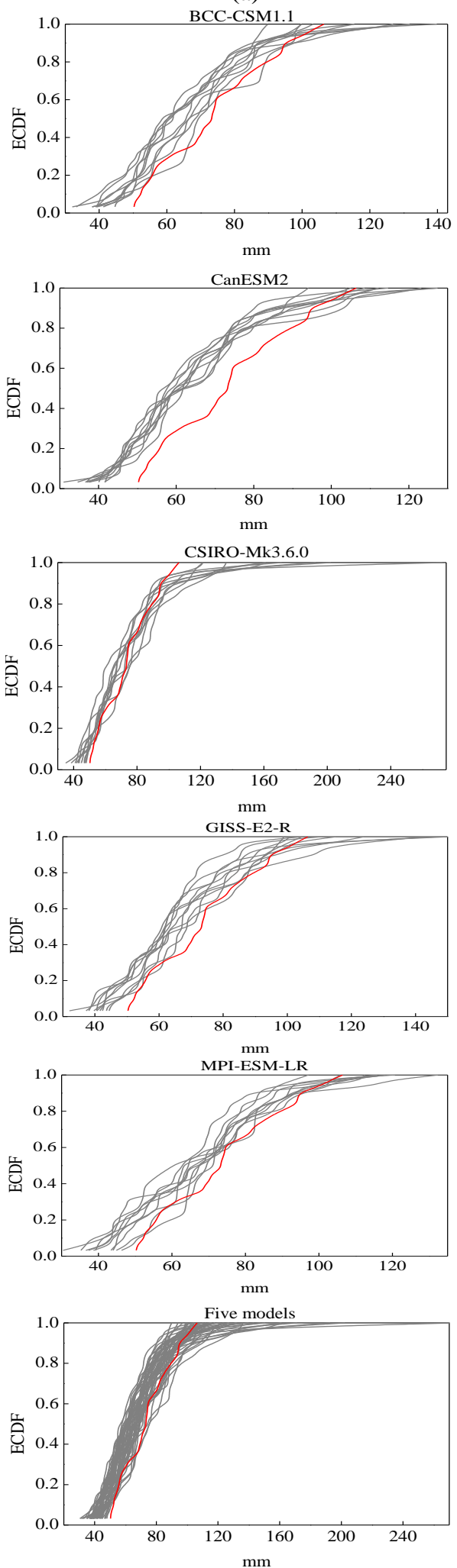

(b)
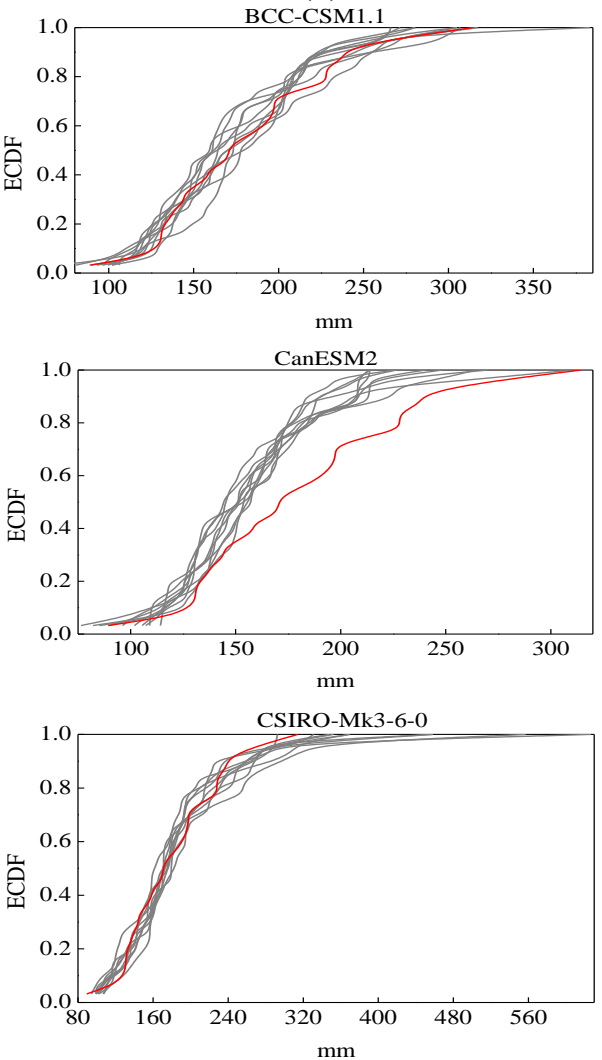

GISS-E2-R
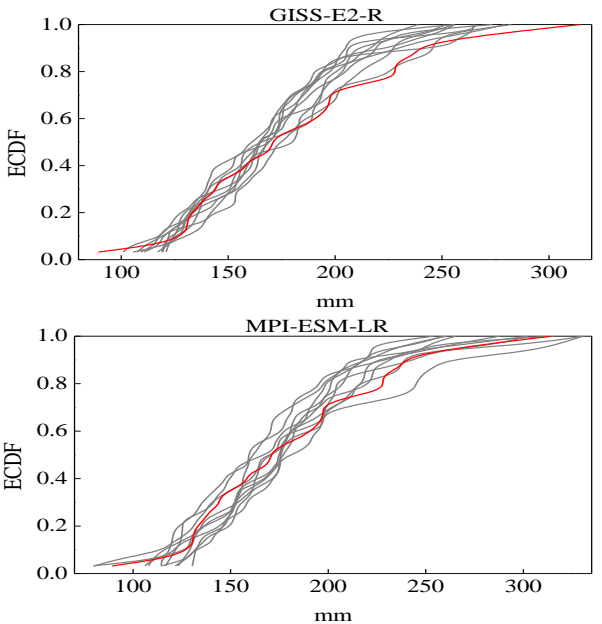

Five models

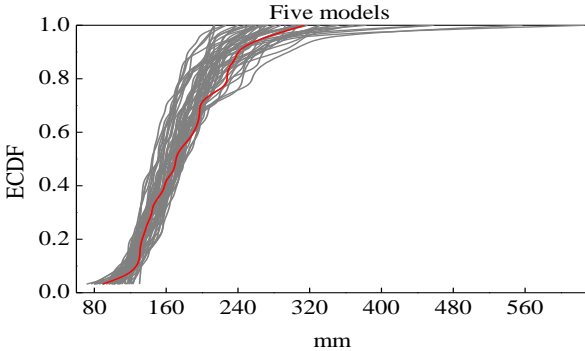

Figure 3. 
(c)
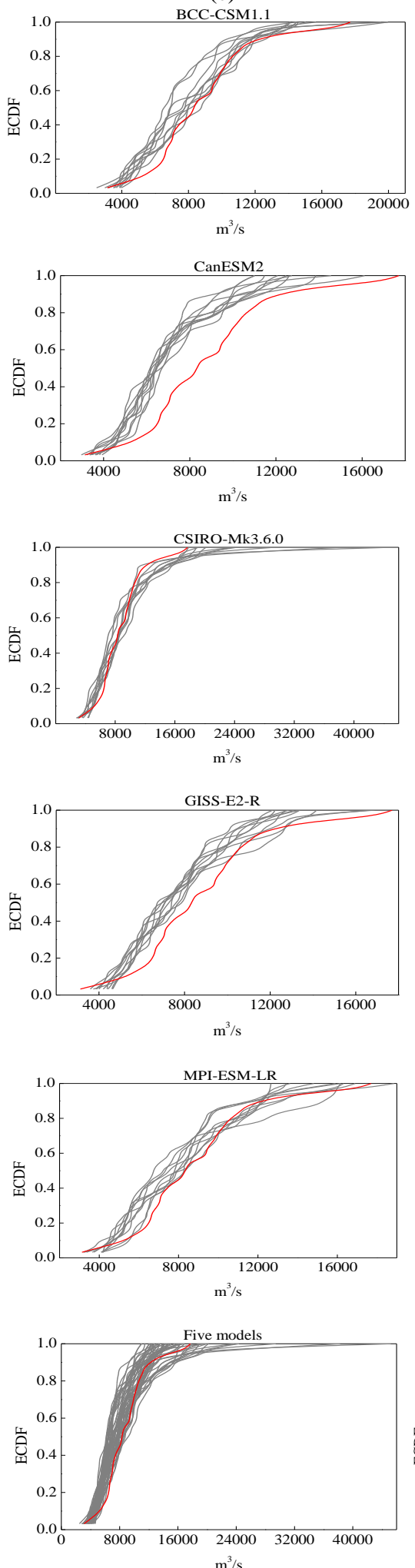

(d)
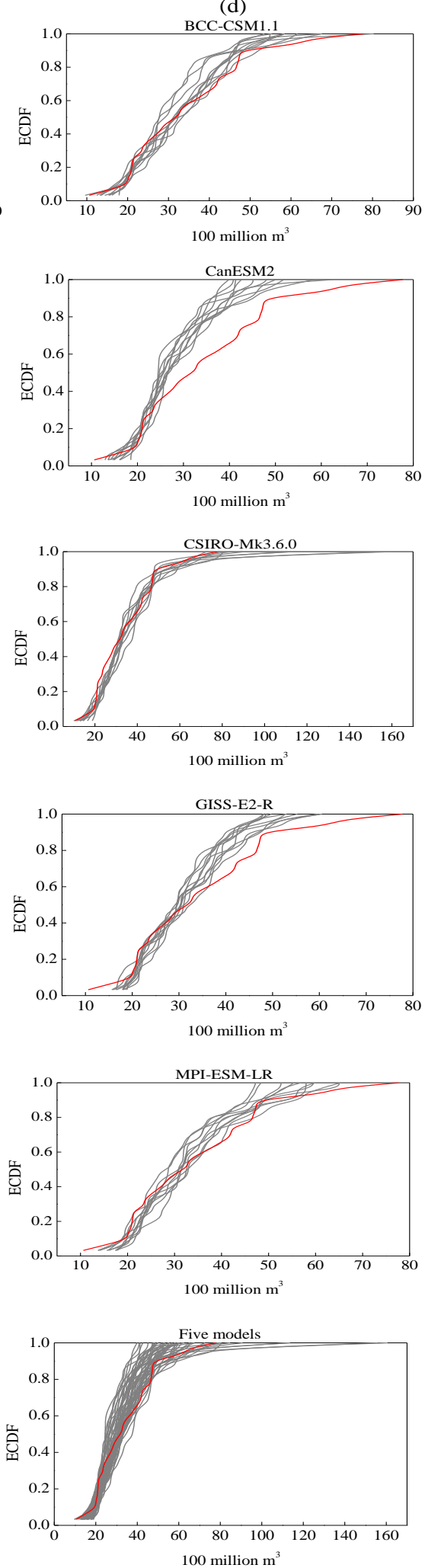

Figure 3. ECDFs for precipitation and floods during the period 1970-2000: (a) observed and downscaled AMX1p, (b) observed and downscaled AMX7p, (c) observed and simulated AMX1d, and (d) observed and simulated AMX7fv. Red line represents the observed. Grey lines represent model simulations. 
of CSIRO-Mk3.6.0, the tail of the distribution of projectiondriven extreme precipitation begins to deviate significantly at the non-exceedance probability of approximately 0.9 to 1.0 . Nevertheless, overall the five GCMs are able to simulate the range of extreme precipitation variability.

\subsection{Evaluation of flood simulations by GCMs}

This section is devoted to an evaluation of the flood simulation ability of each GCM. The VIC model was driven by 10 downscaling simulations for each GCM during the period 1970-2000. Figure 3c and d show the ECDFs of observed and simulated annual maximum 1-day discharges (AMX1d) and maximum 7-day flood volumes (AMX7fv) at the Hengshi hydrologic station during the period 1970-2000.

Compared to Fig. 3a and b, it can be seen that the frequency distribution of extreme floods is very similar to that of precipitation. In contrast, results from individual model ensembles show different characteristics. For example, an overestimation of floods is present in CSIRO-Mk3.6.0, while an underestimation of floods is found in CanESM2 and GISSE2-R; such differences can be explained by the patterns of temperature and precipitation behaviour in each model. However, overall, the simulation sequences from the five GCMs proficiently capture the observed historical extreme floods in the study catchment (five GCMs simulation in Fig. 3c and d); the uncertainty range for changes in flood magnitude is well represented by the five GCMs as a whole.

\subsection{Trend analysis for extreme floods in future periods}

To understand the trends in projected extreme flood events, the trends magnitudes in AMX1d and AMX7fv during two different future periods were calculated (Fig. 4). Overall, the trends magnitudes in the samples for AMX1d and AMX7fv show very similar characteristics during the two future periods. GCMs are often considered to produce a large uncertainty in predictions of future floods, and as expected, there is a difference in projected trends over the study area from the different GCMs. Using the RCP2.6 scenario for example, most samples of AMX1d experience increasing trends in the BCC-CSM1.1, CanESM2 and CSIRO-Mk3.6.0 models during the period 2020-2050. However, few samples with increasing trends can be found in the GISS-E2-R and MPIESM-LR models. Additionally, the uncertainty produced by the emission scenarios is also large here. For the same GCM, the number of samples with increasing trends varies from scenario to scenario. If we examine the BCC-CSM1.1 model for example, there is an increasing trend for most samples of AMX1d and AMX7fv during the period 2020-2050 under the RCP2.6 scenario, but for few samples under the RCP4.5 scenario, and then for approximately half of samples under the RCP8.5 scenario.

Table 1 shows the percentage of samples with increasing trends of AMX1d and AMX7fv in two different future peri- ods, based on five GCMs. According to the definition of assessed likelihood in Sect. 2.4, the credibility of occurrence of the trends in AMX1d and AMX7fv can be described here. In terms of emission scenarios, the largest possibility of increasing trends in AMX1d and AMX7fv is found for the RCP2.6 scenario. In this case, the increasing trends are projected to be more likely than not to occur from 2020-2050, and likely to occur from 2050 to 2080 . In contrast, there is the smallest possibility (about as likely as not) of increasing trends under the RCP4.5 scenario during two different future periods. Under the RCP8.5 scenario, both AMX1d and AMX7fv are more likely than not to show increasing trends in 2020-2050, but in 2050-2080 they are likely and more likely than not to show increasing trends, respectively.

It should be noted here that the uncertainty analysis above focuses on the trend direction without considering the significance level. However, if we consider the trends with a significance level, it can be seen that among the samples with increasing trends, few (no more than $10 \%$ probability) pass the significance test at the 0.1 level, indicating that most of trends in this study are not significant.

\subsection{Uncertainty range for extreme floods in future periods}

This section discusses the uncertainty range of extreme floods during two future periods. Each simulated projection is a 31-year time period for a total of 310 simulated years per scenario. All 310 simulated AMX1d and AMX7fv were pooled to create an uncertainty range for each emission scenario.

From Fig. 6 it can be seen that the projected ranges of AMX1d and AMX7fv display very similar characteristics in all of the different future scenarios of five GCMs. However, there is a relatively large difference in projected changes from different GCMs and emission scenarios. Furthermore, the uncertainty from GCMs is generally larger than that of the emission scenarios. For example, under the RCP2.6 scenario in 2020-2050, the maximum value of AMX1d projected by CanESM2 is less than $18000 \mathrm{~m}^{3} \mathrm{~s}^{-1}$, whereas the maximum value of AMX1d projected by CSIRO-Mk3.6.0 even exceeds $42000 \mathrm{~m}^{3} \mathrm{~s}^{-1}$. In addition, overall, the largest and smallest ranges of AMX1d and AMX7fv are projected by CSIRO-Mk3.6.0 and GISS-E2-R, respectively. Compared to the baseline period 1970-2000, the boxes in Fig. 6 are located in the higher position for most future scenarios of five GCMs, especially for BCC-CSM1.1 and MPI-ESM-LR. This means that the possibility of a projected increase in extreme floods is larger than that of a projected decrease. When comparing two different future periods, it can be found that the projected changes in 2050-2080 would be larger than those in 2020-2050 for most of future scenarios.

To explore the elasticity of floods to extreme precipitation, we show the uncertainty range of precipitation (AMX1p and AMX7p) (Fig. 5), and the percent changes of floods (AMX1d 

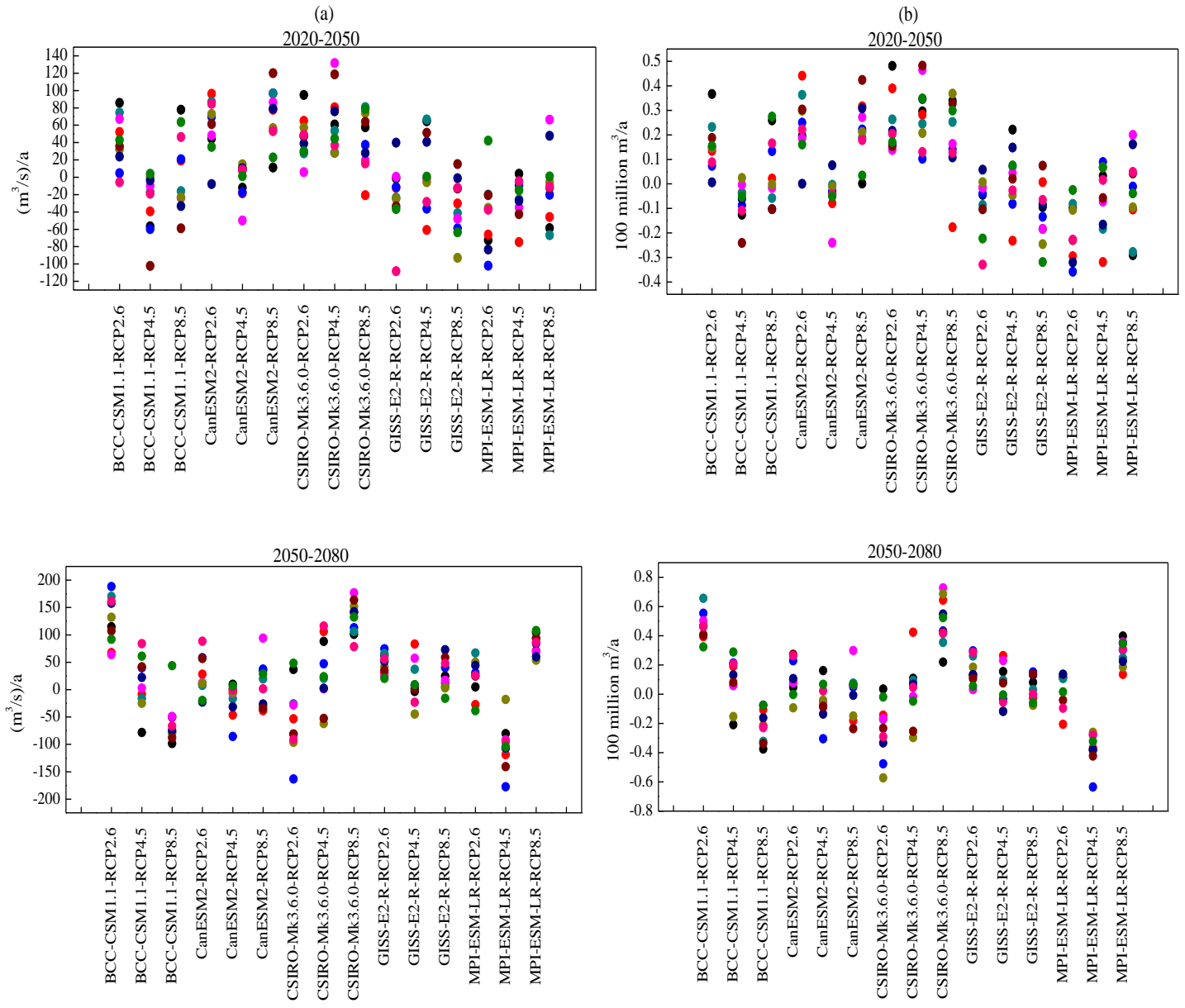

Figure 4. Trends per annum for ten simulated samples of (a) AMX1d and (b) AMX7fv under different emission scenarios.

Table 1. Percentage of samples with increasing trends of AMX1d and AMX7fv in future periods based on five GCMs.

\begin{tabular}{lrrr|rr}
\hline \multirow{2}{*}{$\begin{array}{l}\text { Flood } \\
\text { index }\end{array}$} & Emissions & \multicolumn{2}{c|}{$2020-2050$} & $2050-2080$ \\
\cline { 3 - 6 } & scenarios & IT & SIT & IT & SIT \\
\hline \multirow{3}{*}{ AMX1d } & RCP2.6 & 60 & 10 & 74 & 10 \\
& RCP4.5 & 44 & 2 & 38 & 2 \\
& RCP8.5 & 54 & 2 & 72 & 8 \\
\hline \multirow{3}{*}{ AMX7fv } & RCP2.6 & 60 & 8 & 68 & 10 \\
& RCP4.5 & 44 & 2 & 44 & 0 \\
& RCP8.5 & 58 & 2 & 62 & 10 \\
\hline
\end{tabular}

IT, increasing trend; SIT, significant increasing trend (significant at the 0.1 level)

and AMX7fv) in response to the precipitation (AMX1p and AMX7p) (Table 2). A comparison of Figs. 5 and 6 shows that the projected ranges of precipitation and floods display very similar characteristics in all of the different future scenarios of five models. In addition, the projected changes in floods are found to be closely associated with the changes in precipitation during the two future periods (Table 2). For example in the case of CanESM2, when the AMX1p increases $4.55,17.84$, and $9.72 \%$ during the period 2020 2050 under the RCP2.6, RCP4.5, and RCP8.5 scenarios, respectively, the AMX1d increases 2.35, 19.86, and $11.94 \%$, respectively. In contrast, there are some inconsistences between precipitation and floods for some models. For example, the AMX1p increases $0.52 \%$ in 2020-2050 under the RCP2.6 scenario of the BCC-CSM1.1 model, whereas the AMX1d decreases $-5.54 \%$. This indicates that the projected changes in floods are influenced not only by precipitation but also by other climate-related factors, such as temperature. However, overall, the flood changes are very sensitive to precipitation changes in the study region.

\subsection{Average changes in extreme floods in future periods}

Based on 10 simulations for each emission scenario, the average changes in extreme floods for each future scenario are analysed in this section. Here, the average for each future scenario is the arithmetic average of 10 simulations. To compare the frequency of extreme floods between baseline and 
(a)
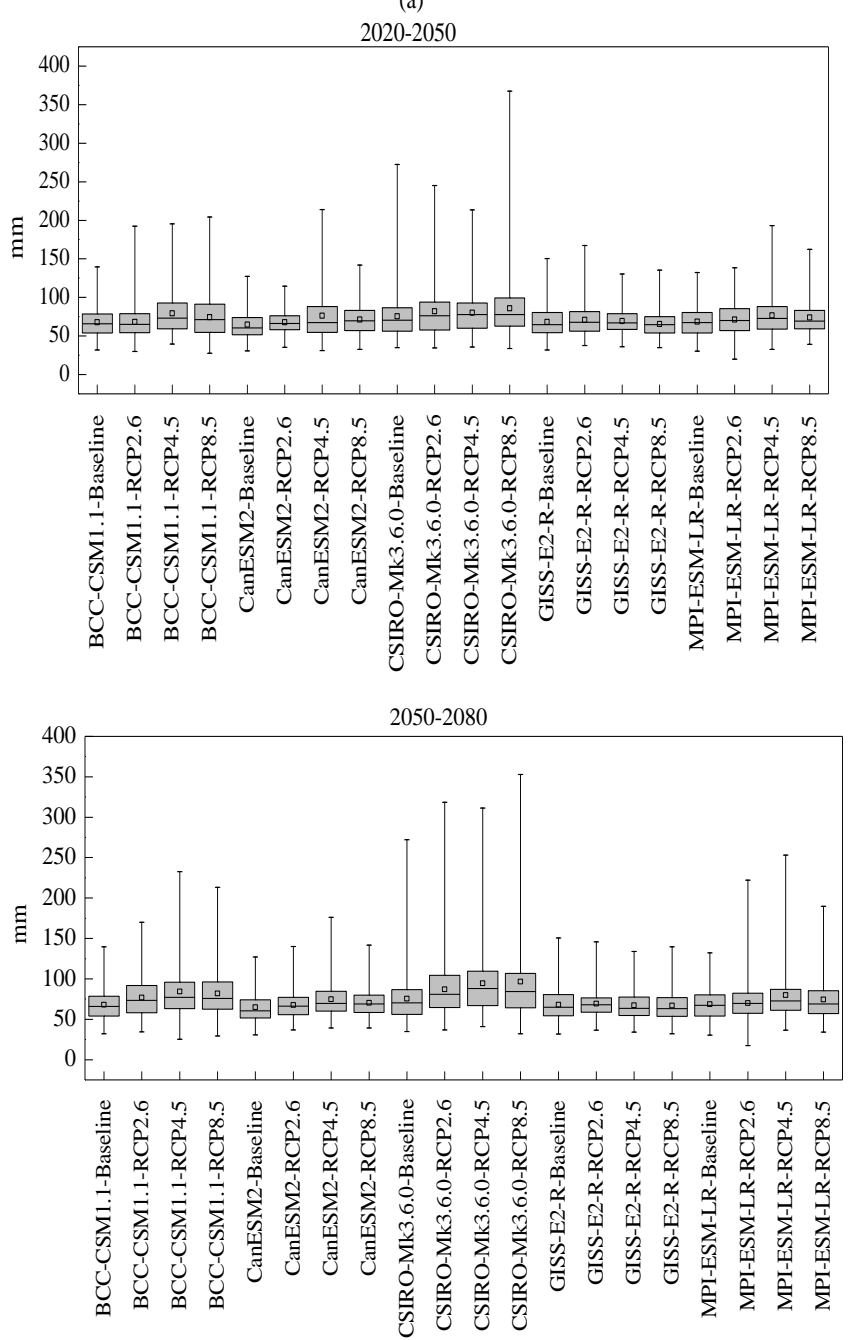

(b)
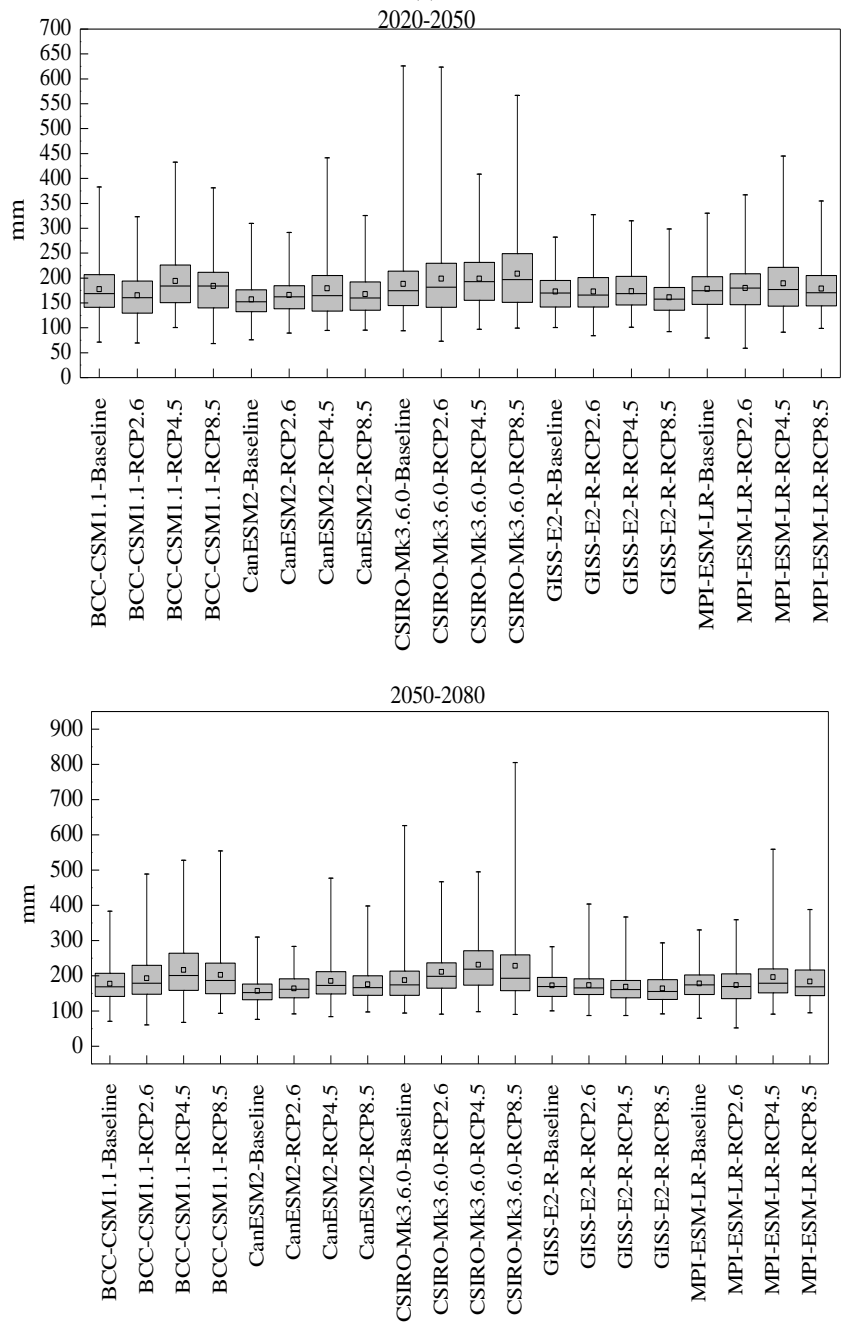

Figure 5. Uncertainty range of (a) AMX1p and (b) AMX7p under different emission scenarios. Box plots: the central mark is the median; the small square inside the box is the average; the box edges are the 25th and 75th percentiles; the whiskers extend to the 1st and 99th percentiles.

future periods, P-III frequency distributions are plotted for comparison (Fig. 7). When the frequency is less than $10 \%$, most future scenarios of the five models suggest a rather similar increasing trend in AMX1d and AMX7fv, where the largest projected increases (absolute change) are found for the CSIRO-Mk3.6.0 model, and the smallest increases for the GISS-E2-R model. In terms of two different future periods, the projected increases in 2050-2080 are larger than those in 2020-2050 for most future scenarios. In particular, the BCCCSM1.1 model projects a maximum increase $(p<10 \%)$ in AMX1d and AMX7fv for the RCP4.5 and RCP8.5 scenarios during 2050-2080 and a minimum increase for the RCP2.6 scenario during 2020-2050. For the CanESM2 model, a maximum increase $(p<10 \%)$ is found for the RCP4.5 scenario during 2020-2050, while the opposite tendency (decrease) is found for the RCP2.6 scenario during both 2020
2050 and 2050-2080. CSIRO-Mk3.6.0 projects a large increase in AMX1d and AMX7fv for the RCP2.6 scenario during 2020-2050 and for the RCP8.5 scenario in 20502080 , but projects a clear reduction for the RCP4.5 scenario in 2020-2050. Compared to other models, the GISS-E2-R model projects a relatively small change in future periods, where there is a maximum increase for the RCP2.6 scenario during 2050-2080 and a maximum decrease for the RCP8.5 scenario during 2020-2050. For the MPI-ESM-LR model, the projected increases are found for all of the different future scenarios, which is similar to that of the BCC-CSM1.1 model.

To further investigate the percentage changes in AMX1d and AMX7fv, three different return periods ( $100 \mathrm{yr}, 50 \mathrm{yr}$ and $20 \mathrm{yr}$ ) were chosen (Table 3). Due to the uncertainty from GCMs, there is a relatively large variability in the results 
Table 2. Percentage changes (\%) in AMX1p, AMX7p, AMX1d and AMX7fv under different scenarios (relative to the baseline period 1970-2000)

\begin{tabular}{lrrrrrr|rrrrrr}
\hline Index & Emissions & \multicolumn{9}{c}{$2020-2050$} & & \multicolumn{3}{c}{$2050-2080$} \\
\cline { 3 - 13 } & scenarios & $\mathrm{a}$ & $\mathrm{b}$ & $\mathrm{c}$ & $\mathrm{d}$ & $\mathrm{e}$ & $\mathrm{a}$ & $\mathrm{b}$ & $\mathrm{c}$ & $\mathrm{d}$ & $\mathrm{e}$ \\
\hline \multirow{3}{*}{ AMX1p } & RCP2.6 & 0.52 & 4.55 & 8.60 & 3.99 & 3.52 & 13.33 & 4.42 & 15.01 & 1.87 & 2.01 \\
& RCP4.5 & 17.19 & 17.84 & 5.78 & 2.09 & 11.45 & 24.51 & 15.33 & 25.20 & -1.32 & 16.42 \\
& RCP8.5 & 9.57 & 9.72 & 13.55 & -3.78 & 7.48 & 20.85 & 8.37 & 27.74 & -1.73 & 8.61 \\
\hline \multirow{3}{*}{ AMX1d } & RCP2.6 & -5.54 & 2.35 & 1.70 & 4.52 & 5.62 & 12.59 & 3.01 & 14.26 & 1.18 & 0.55 \\
& RCP4.5 & 17.09 & 19.86 & 1.08 & 1.55 & 8.75 & 32.57 & 21.46 & 26.69 & -2.09 & 13.57 \\
& RCP8.5 & 7.50 & 11.94 & 6.36 & -10.05 & 0.78 & 22.27 & 13.06 & 30.05 & -5.08 & 4.93 \\
\hline \multirow{3}{*}{ AMX7p } & RCP2.6 & -6.69 & 5.54 & 5.78 & -0.12 & 0.66 & 8.88 & 4.58 & 12.25 & 0.39 & -2.89 \\
& RCP4.5 & 9.43 & 14.17 & 5.79 & 0.22 & 6.18 & 22.02 & 17.79 & 23.25 & -2.42 & 9.96 \\
& RCP8.5 & 3.88 & 6.58 & 11.08 & -6.60 & 0.14 & 14.03 & 11.98 & 21.43 & -5.18 & 3.00 \\
\hline \multirow{3}{*}{ AMX7fv } & RCP2.6 & -6.85 & 2.97 & 1.00 & 3.31 & 5.62 & 11.95 & 2.81 & 14.41 & 1.29 & -1.32 \\
& RCP4.5 & 12.55 & 18.25 & 0.44 & 1.21 & 7.40 & 29.77 & 22.03 & 27.80 & -2.33 & 11.09 \\
& RCP8.5 & 4.01 & 10.35 & 6.37 & -10.25 & -0.91 & 18.70 & 13.32 & 28.03 & -4.91 & 3.41 \\
\hline
\end{tabular}

a, BCC-CSM1.1; b, CanESM2; c, CSIRO-Mk3.6.0; d, GISS-E2-R; e, MPI-ESM-LR
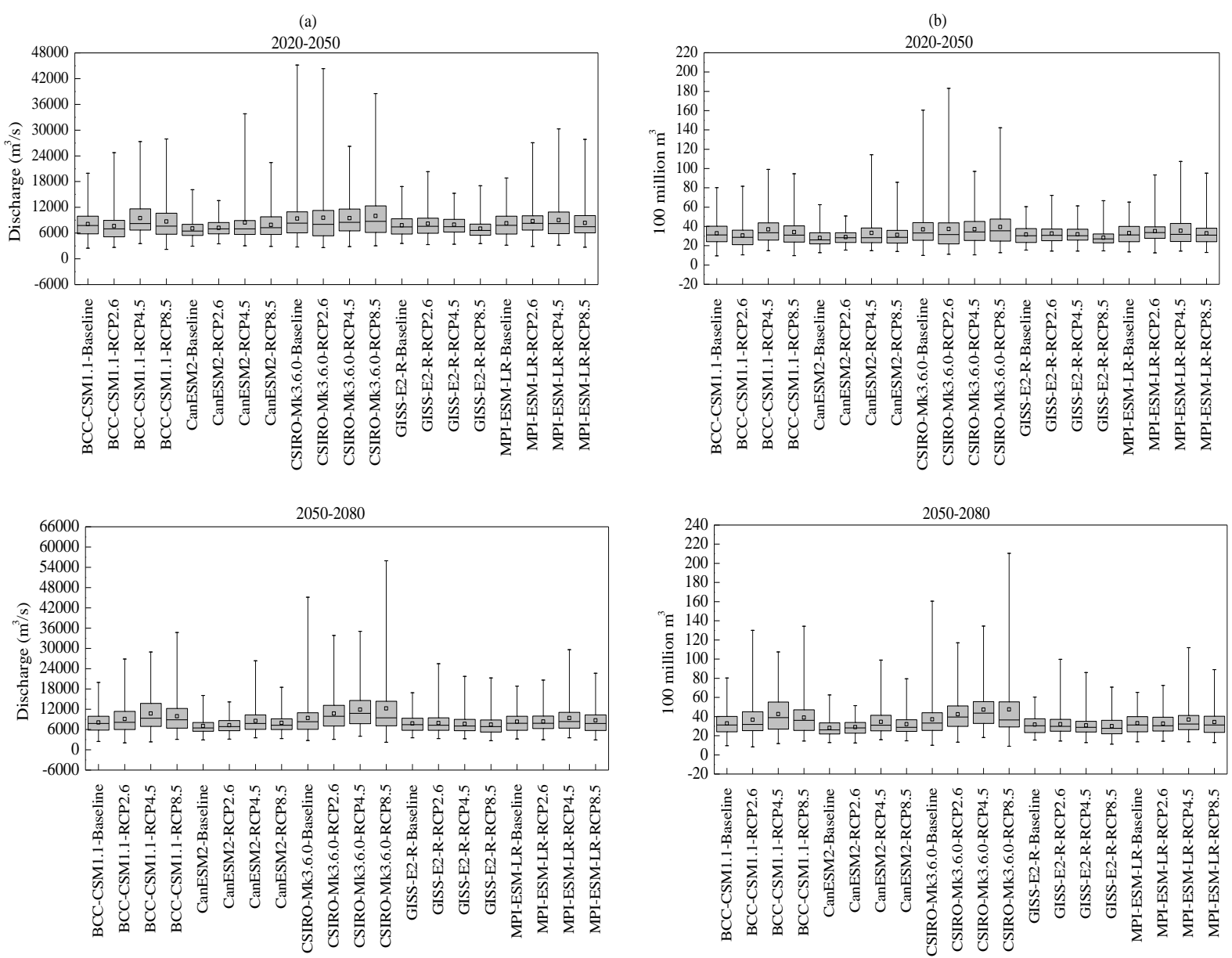

Figure 6. Uncertainty range of (a) AMX1d and (b) AMX7fv under different emission scenarios. Box plots: the central mark is the median; the small square inside the box is the average; the box edges are the 25th and 75th percentiles; the whiskers extend to the 1st and 99th percentiles. 
(a)
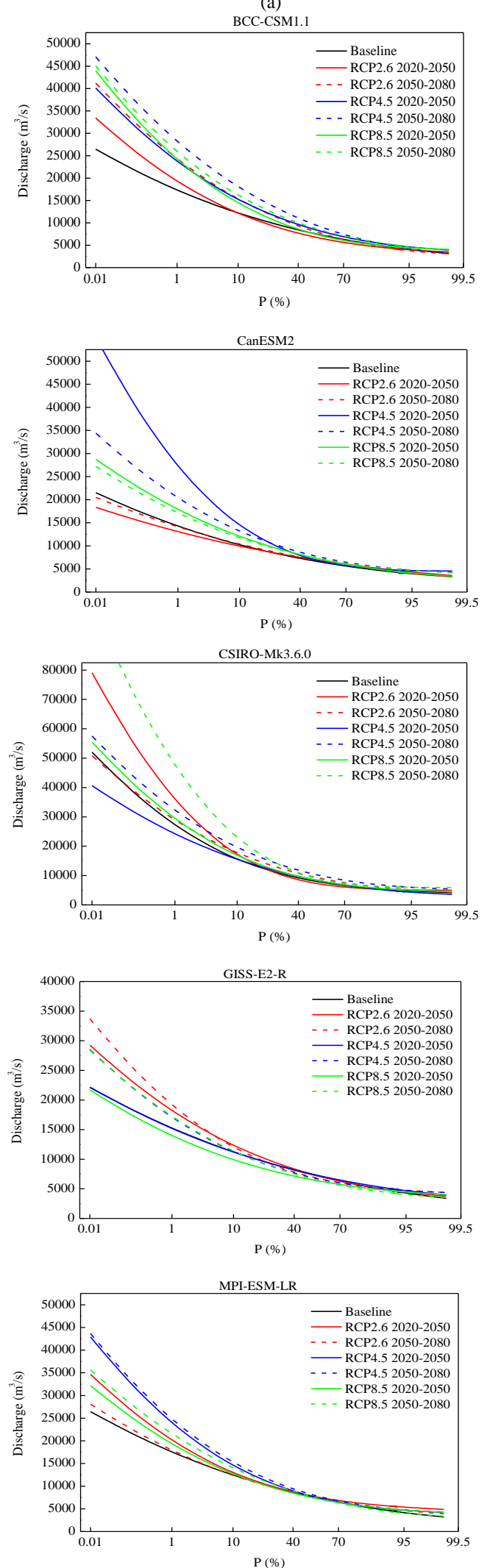

(b)
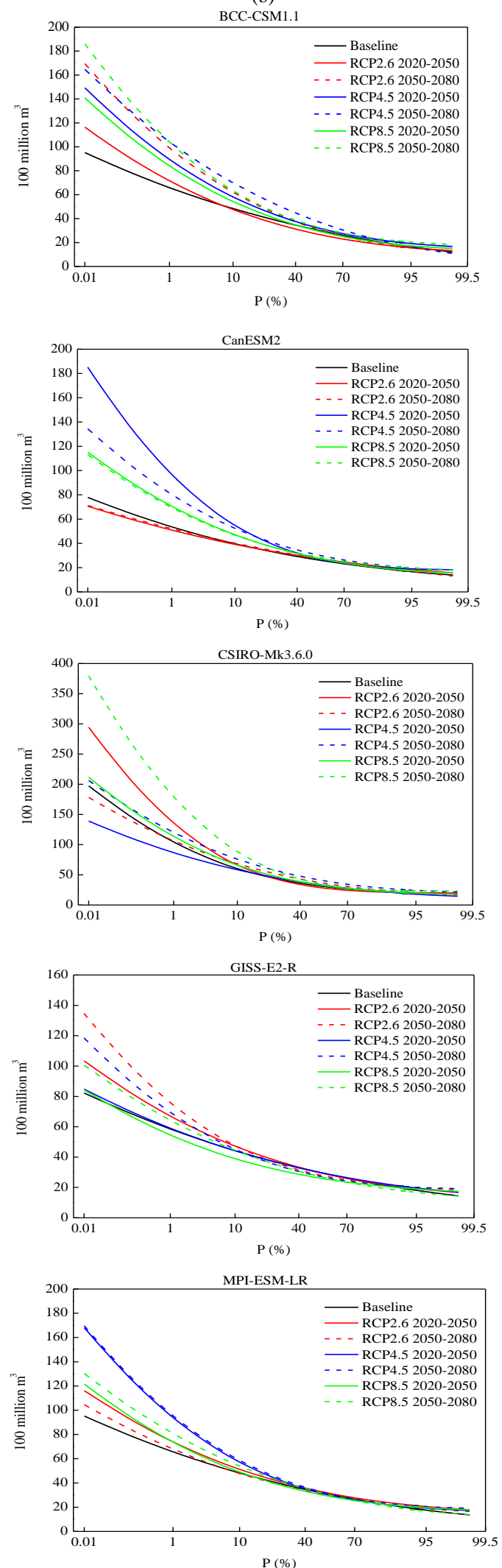

Figure 7. P-III frequency distributions of (a) AMX1d and (b) AMX7fv under different emission scenarios during two different future periods. 
from the five GCMs. Nevertheless, most of GCMs project an increase during two future periods. As shown in Table 3, the largest percentage increases in AMX1d and AMX7fv are mainly found for the RCP4.5 scenario of the CanESM2 model in 2020-2050 (91.0\% in AMX1d and $80.1 \%$ in AMX7fv for the $100 \mathrm{yr}$ return period). In comparison, the largest percentage decreases in AMX1d and AMX7fv are mainly found for the RCP4.5 scenario of the CSIRO-Mk3.6.0 model in $2020-2050(-11.3 \%$ in AMX1d and $-16.8 \%$ in AMX7fv for the $100 \mathrm{yr}$ return period). When considering the results from all future scenarios of the five models, the range of percentage changes are described here. For AMX1d, the percentage changes in the 100-year return period range from -11.3 to $91 \%$ in $2020-2050$, and from -1.2 to $74.7 \%$ in 2050-2080. For AMX7fv, the percentage changes in the 100year return period range from -16.8 to $80.1 \%$ in $2020-2050$, and from -2.9 to $71.8 \%$ in 2050-2080 (Table 3).

\section{Discussion}

The impact of climate change on extreme floods in the Beijiang River basin were analysed in this study, and the majority of modelling results informed by the five CMIP5 GCMs show a projected increase in floods. These findings are somewhat consistent with several previous studies. Xiao et al. (2013) concluded that the risk of flood in the Beijiang River basin would be more likely than not to increase under the RCP4.5 scenario. Based on four emission scenarios (A1B, RCP2.6, RCP4.5, and RCP8.5), Wu et al. (2014b) found an increase of $4.35-9.18 \%$ in the 500-year return period for daily discharge in the upstream of the Beijiang River basin. Evidence has been obtained to show that the Beijiang River basin is likely to experience an increase in episodes of flooding in the following several decades.

In this study, we used five GCMs, three emission scenarios, 10 downscaling simulations for each emission scenario, two stages of the future period, and one hydrological model to discuss the possible range of projected changes in extreme floods. The results indicate that GCMs and emission scenarios produce a large range of uncertainty in flood projections in future climate conditions, which corroborates the previous findings of Chen et al. (2011), Kay et al. (2009), and Prudhomme and Davies (2009). In other words, the inconsistency in the projected changes (as produced by the various GCMs and the emission scenarios) highlights the impact of potential misleading conclusions if only one GCM scenario were to be used for impact studies. Meanwhile, it should be kept in mind that some other uncertainty sources, such as downscaling techniques and the hydrological model structure and its parameters, were overlooked in this study. Several previous studies have shown that the uncertainty sourced from the GCMs is much larger than those in downscaling techniques and hydrological models (Prudhomme and Davies, 2009; Teng et al., 2012), although this does not imply that uncertainty stemming from downscaling techniques and hydrological models should be ignored in impact studies. Taking the VIC model used in this study as an example, daily estimations of evapotranspiration (ET) in the model are made according to information received for relative humidity, wind speed, and long- and short-wave incoming radiation (Bohn et al., 2013). However, due to the limited coverage of meteorological data, VIC is normally forced by daily data of maximum and minimum temperatures and precipitation, which is a common practice in many studies worldwide (e.g. Wu et al., 2014b; Xiao et al., 2013). Pierce et al. (2013) found that this approach can result in opposite humidity trends for GCMs, which then affect simulated runoff under future scenarios. In addition, when using a hydrological model to assess the impact of climate change, there is an implicit assumption that the hydrological model parameters calibrated from observations remain valid for future climatic conditions (Xu et al., 2013). However, Merz et al. (2011) pointed that hydrological model parameters may potentially change if calibrated to different periods, and such a concept has important implications in climate impact analyses. Therefore, a next step of this study is a thorough investigation of the uncertainty produced by hydrological model (VIC) structure and its parameters in the projection of impact of climate change on floods.

To highlight the uncertainty of the results, this paper attempts to describe the credibility of projected flood changes with an approach using uncertainty expressions, as recommended by the AR5. This provides a quantitative basis for estimating likelihoods for many aspects of future climate change. However, the results should be taken with care, as the likelihood scheme itself is inappropriate for use in subjective evaluation and needs to be supplemented with a qualitative framework (Risbey and Kandlikar, 2007). Use of a best combination of levels of confidence with likelihood, which provides more powerful means for analysts to express uncertainty, should be considered in future work.

\section{Conclusions}

Based on five CMIP5 GCMs, this paper discusses the potential impacts of climate change on extreme floods in the Beijiang River basin. The VIC model was employed to simulate daily discharge, using $0.25^{\circ}$ grid cells across the study area for the historical period (1970-2000) and for two different future periods (2020-2050 and 2050-2080). Two flood indexes (AMX1d and AMX7fv) were chosen for use in analysis, and uncertainty in future flood trends was considered by using an uncertainty expressions approach.

Validation of the VIC model suggests that it performs well in simulating both daily streamflow and extreme floods, and can thus be used to estimate the potential impacts of climate change on floods. Modelling results show that there are large uncertainties sourced from GCMs and emission scenarios. Overall, the uncertainty range for changes in historical ex- 
Table 3. Percentage changes (\%) in AMX1d and AMX7fv for different return periods under different scenarios (relative to the baseline period 1970-2000).

\begin{tabular}{|c|c|c|c|c|c|c|c|c|}
\hline \multirow{2}{*}{$\begin{array}{l}\text { Flood } \\
\text { index }\end{array}$} & \multirow{2}{*}{$\begin{array}{r}\text { Return } \\
\text { period }(\mathrm{yr})\end{array}$} & \multirow[t]{2}{*}{ GCM } & \multicolumn{2}{|c|}{$\mathrm{RCP} 2.6$} & \multicolumn{2}{|l|}{$\mathrm{RCP} 4.5$} & \multicolumn{2}{|c|}{ RCP8.5 } \\
\hline & & & $\mathrm{T} 1$ & $\mathrm{~T} 2$ & $\mathrm{~T} 1$ & $\mathrm{~T} 2$ & $\mathrm{~T} 1$ & $\mathrm{~T} 2$ \\
\hline \multirow{15}{*}{ AMX1d } & \multirow{5}{*}{100} & BCC-CSM1.1 & 11.4 & 40.2 & 37.1 & 62.9 & 39.8 & 49.6 \\
\hline & & CanESM2 & -8.5 & -1.2 & 91 & 42.7 & 25.2 & 19.7 \\
\hline & & CSIRO-Mk3.6.0 & 32 & 6 & -11.3 & 18.2 & 8 & 74.7 \\
\hline & & GISS-E2-R & 19.5 & 25.7 & -0.5 & 12 & -8.2 & 12.8 \\
\hline & & MPI-ESM-LR & 15 & 2.1 & 36.8 & 41.3 & 10.3 & 23 \\
\hline & \multirow{5}{*}{50} & BCC-CSM1.1 & 8.3 & 36.6 & 33.9 & 59.3 & 34.1 & 45.1 \\
\hline & & CanESM2 & -7.1 & -0.4 & 77.4 & 39 & 23.3 & 18.4 \\
\hline & & CSIRO-Mk3.6.0 & 26.7 & 8.1 & -8.5 & 20.2 & 8.2 & 68.4 \\
\hline & & GISS-E2-R & 16.8 & 20.5 & -0.5 & 8.7 & -9.4 & 9.6 \\
\hline & & MPI-ESM-LR & 11.9 & 1.3 & 31.5 & 36.3 & 8 & 20.4 \\
\hline & \multirow{5}{*}{20} & BCC-CSM1.1 & 3.5 & 30.9 & 29.0 & 53.5 & 25.5 & 38.3 \\
\hline & & CanESM2 & -4.8 & 0.7 & 57.3 & 33.5 & 20.4 & 16.3 \\
\hline & & CSIRO-Mk3.6.0 & 17.8 & 11.4 & -4.0 & 23.3 & 8.4 & 57.6 \\
\hline & & GISS-E2-R & 12.9 & 12.9 & -0.6 & 3.9 & -10.9 & 4.9 \\
\hline & & MPI-ESM-LR & 7.5 & 0.2 & 23.5 & 28.8 & 4.6 & 16.3 \\
\hline \multirow{15}{*}{ AMX7fv } & \multirow{5}{*}{100} & BCC-CSM1.1 & 8.6 & 50.3 & 35.8 & 58.1 & 27.6 & 57.8 \\
\hline & & CanESM2 & -5.2 & -2.9 & 80.1 & 49.5 & 31.6 & 29.2 \\
\hline & & CSIRO-Mk3.6.0 & 30.2 & 1.8 & -16.8 & 15.2 & 9 & 71.8 \\
\hline & & GISS-E2-R & 14.5 & 29.5 & 0.9 & 18.7 & -6.8 & 9.8 \\
\hline & & MPI-ESM-LR & 12.4 & 3.4 & 42.9 & 45.2 & 12.2 & 23 \\
\hline & \multirow{5}{*}{50} & BCC-CSM1.1 & 5.9 & 44.4 & 31.5 & 54.7 & 23.5 & 50.3 \\
\hline & & CanESM2 & -4.2 & -1.7 & 68.5 & 44.7 & 28.2 & 26.1 \\
\hline & & CSIRO-Mk3.6.0 & 25.1 & 4.8 & -13.4 & 18 & 9.3 & 66 \\
\hline & & GISS-E2-R & 12.3 & 23.1 & 0.6 & 13.9 & -8.4 & 7.3 \\
\hline & & MPI-ESM-LR & 10.6 & 2.2 & 36.1 & 38.6 & 9.2 & 20 \\
\hline & \multirow{5}{*}{20} & BCC-CSM1.1 & 1.7 & 35.5 & 25.2 & 49.3 & 17.3 & 39.2 \\
\hline & & CanESM2 & -2.7 & 0.0 & 51.4 & 37.6 & 23.0 & 21.4 \\
\hline & & CSIRO-Mk3.6.0 & 16.7 & 9.6 & -7.9 & 22.5 & 9.7 & 55.9 \\
\hline & & GISS-E2-R & 9.1 & 14.0 & 0.1 & 7.0 & -10.6 & 3.6 \\
\hline & & MPI-ESM-LR & 8.0 & 0.4 & 26.2 & 28.9 & 4.9 & 15.5 \\
\hline
\end{tabular}

T1, 2020-2050; T2, 2050-2080

treme precipitation and flood magnitude can be well represented by the five GCMs.

Trend analysis of projected extreme floods indicates that AMX1d and AMX7fv show very similar trends during the two future periods (2020-2050 and 2050-2080). The largest possibilities (more likely than not and likely) of increasing trends in AMX1d and AMX7fv were found for the RCP2.6 scenario, whereas the smallest possibilities (about as likely as not) of increasing trends were found for the RCP4.5 scenario. There is a relatively large variability in the projected ranges of AMX1d and AMX7fv under the different future scenarios in the five GCMs. However, most of models projected an increase during the two future periods (relative to the baseline period 1970-2000). Overall, the percentage changes in the 100-year return period AMX1d ranged from -11.3 to $91 \%$, while the percentage changes in the 100-year return period AMX7fv ranged from -16.8 to $80.1 \%$. It must be emphasized here that these results should be taken with care, as some other uncertainty sources, such as downscaling techniques and the hydrological model structure and its parameters, were overlooked in this study. A thorough investigation of more uncertainty in the projection of impact of climate change on floods should be considered in future work.

Acknowledgements. This study was supported by the National Basic Research Program of China (2010CB428405) and the Special Funds for Public Welfare Projects of the Ministry of Water Resources of China (201301093). The GCMs data were kindly provided by Zhiyong $\mathrm{Wu}$ and Heng Xiao from Hohai University.

Edited by: P. Gentine 


\section{References}

Bennett, J. C., Grose, M. R., Corney, S. P., White, C. J., Holz, G. K., Katzfey, J. J., Post, D. A., and Bindoff, N. L.: Performance of an empirical bias-correction of a high-resolution climate dataset, Int. J. Climatol., 34, 2189-2204, 2014.

Bohn, T. J., Livneh, B., Oyler, J. W., Running, S. W., Nijssen, B., and Lettenmaier, D. P.: Global evaluation of MTCLIM and related algorithms for forcing of ecological and hydrological models, Agric. For. Meteorol., 176, 38-49, 2013.

Chen, J., Brissette, F. P., Poulin, A., and Leconte, R.: Overall uncertainty study of the hydrological impacts of climate change for a Canadian watershed, Water Resour. Res., 47, W12509, doi:10.1029/2011WR010602, 2011.

Feyen, L., Dankers, R., Bódis, K., Salamon, P., and Barredo, J. I.: Fluvial flood risk in Europe in present and future climates, Clim. Change, 112, 47-62, 2012.

Fowler, H. J., Blenkinsop, S., and Tebaldi, C.: Linking climate change modelling to impacts studies: recent advances in downscaling techniques for hydrological modelling, Int. J. Climatol., 27, 1547-1578, 2007.

Gulizia, C. and Camilloni, I.: Comparative analysis of the ability of a set of CMIP3 and CMIP5 global climate models to represent precipitation in South America, Int. J. Climatol., doi:10.1002/joc.4005, in press, 2015.

Hansen, M. C., Defries, R. S., Townshend, J. R. G., and Sohlberg, R.: Global land cover classification at $1 \mathrm{~km}$ spatial resolution using a classification tree approach, Int. J. Remote Sens., 21, 13311364, 2000.

Huang, S., Hattermann, F. F., Krysanova, V., and Bronstert, A.: Projections of climate change impacts on river flood conditions in Germany by combining three different RCMs with a regional eco-hydrological model, Clim. Change, 116, 631-663, 2013.

IPCC: Climate Change 2013: The Physical Science Basis. Contribution of Working Group I to the Fifth Assessment Report of the Intergovernmental Panel on Climate Change, edited by: Stocker, T. F., Qin, D., Plattner, G.-K., Tignor, M., Allen, S. K., Boschung, J., Nauels, A., Xia, Y., Bex, V., and Midgley, P. M., Cambridge University Press, Cambridge, United Kingdom and New York, NY, USA, 1535 pp., 2013.

Kay, A. L. and Jones, D. A.: Transient changes in flood frequency and timing in Britain under potential projections of climate change, Int. J. Climatol., 32, 489-502, 2012.

Kay, A. L., Davies, H. N., Bell, V. A., and Jones, R. G.: Comparison of uncertainty sources for climate change impacts: flood frequency in England, Clim. Change, 92, 41-63, 2009.

Kendall, M. G.: Rank Correlation Methods, 4th edn. Charles Griffin: London, UK, 1975.

Li, H., Sheffield, J., and Wood, E. F.: Bias correction of monthly precipitation and temperature fields from Intergovernmental Panel on Climate Change AR4 models using equidistant quantile matching, J. Geophys. Res.-Atmos., 115, D10101, doi:10.1029/2009JD012882, 2010.

Liang, X., Lettenmaier, D. P., Wood, E. F., and Burges, S. J.: A simple hydrologically based model of land surface water and energy fluxes for general circulation models, J. Geophys. Res.-Atmos., 99, 14415-14428, 1994.

Liu, L. L., Fischer, T., Jiang, T., and Luo, Y.: Comparison of uncertainties in projected flood frequency of the Zhujiang River, South China, Quatern. Int., 304, 51-61, 2013.
Mann, H. B.: Non-Parametric tests against trend, Econometrica, 13, 245-259, 1945.

Merz, R., Parajka, J., and Blöschl, G.: Time stability of catchment model parameters: Implications for climate impact analyses, Water Resour. Res., 47, W02531, doi:10.1029/2010WR009505, 2011.

Mirza, M. M. Q., Warrick, R. A., and Ericksen, N. J.: The implications of climate change on floods of the Ganges, Brahmaputra and Meghna rivers in Bangladesh, Clim. Change, 57, 287-318, 2003.

Moss, R. H., Edmonds, J. A., Hibbard, K. A., Manning, M. R., Rose, S. K., van Vuuren, D. P., Carter, T. R., Emori, S., Kainuma, M., Kram, T., Meehl, G. A., Mitchell, J. F. B., Nakicenovic, N., Riahi, K., Smith, S. J., Stouffer, R. J., Thomson, A. M., Weyant, J. P., and Wilbanks, T. J.: The next generation of scenarios for climate change research and assessment, Nature, 463, 747-756, 2010.

Nijssen, B., Lettenmaier D. P., Liang X., Wetzel S. W., and Wood E. F.: Streamflow simulation for continental-scale river basins, Water Resour. Res., 33, 711-724. 1997.

Pennell, C. and Reichler, T.: On the Effective Number of Climate Models, J. Clim., 24, 2358-2367, 2011.

Pierce, D. W., Westerling, A. L., and Oyler, J.: Future humidity trends over the western United States in the CMIP5 global climate models and variable infiltration capacity hydrological modeling system, Hydrol. Earth Syst. Sci., 17, 1833-1850, doi:10.5194/hess-17-1833-2013, 2013.

Pincus, R., Batstone, C. P., Hofmann, R. J. P., Taylor, K. E., and Glecker, P. J.: Evaluating the present-day simulation of clouds, precipitation, and radiation in climate models, J. Geophys. ResAtmos., 113, D14209, 2008.

Prudhomme, C. and Davies, H. N.: Assessing uncertainties in climate change impact analyses on river flow regimes in the UK. Part 2: future climate, Clim. Change, 93, 197-222, 2009.

Raff, D. A., Pruitt, T., and Brekke, L. D.: A framework for assessing flood frequency based on climate projection information, Hydrol. Earth Syst. Sci., 13, 2119-2136, doi:10.5194/hess-13-21192009, 2009.

Risbey, J. S. and Kandlikar, M.: Expressions of likelihood and confidence in the IPCC uncertainty assessment process, Clim. Change, 85, 19-31, 2007.

Sachindra, D. A., Huang, F., Barton, A., and Perera, B. J. C.: Statistical downscaling of general circulation model outputs to precipitation-part 1: calibration and validation, Int. J. Climatol., 34, 3264-3281, doi:10.1002/joc.3914, 2014a.

Sachindra, D. A., Huang, F., Barton, A., and Perera, B. J. C.: Statistical downscaling of general circulation model outputs to precipitation - Part 2: bias-correction and future projections, Int. J. Climatol., 34, 3282-3303, doi:10.1002/joc.3915, 2014b.

Sen, P. K.: Estimates of the regression coefficient based on Kendall's tau, J. Am. Stat. Assoc., 63, 1379-1389, 1968.

Smith, I., Syktus, J., McAlpine, C., and Wong, K.: Squeezing information from regional climate change projections-results from a synthesis of CMIP5 results for south-east Queensland, Australia, Clim. Change, 121, 609-619, 2013.

Taylor, K. E., Stouffer, R. J., and Meehl, G. A.: An Overview of CMIP5 and the Experiment Design, B. Am. Meteorol. Soc., 93, 485-498, 2012.

Teng, J., Vaze, J., Chiew, F. H. S., Wang, B., and Perraud, J.: Estimating the Relative Uncertainties Sourced from GCMs and 
Hydrological Models in Modeling Climate Change Impact on Runoff, J. Hydrometeor., 13, 122-139, 2012.

Tisseuil, C., Vrac, M., Lek, S., and Wade, A. J.: Statistical downscaling of river flows, J. Hydrol., 385, 279-291, 2010.

Wang, G. Q., Zhang, J. Y., Jin, J. L., Pagano, T. C., Calow, R., Bao, Z. X., Liu, C. S., Liu, Y. L., and Yan, X. L.: Assessing water resources in China using PRECIS projections and a VIC model, Hydrol. Earth Syst. Sci., 16, 231-240, doi:10.5194/hess-16-2312012, 2012.

Wong, K. K. and Zhao, X.: Living with floods: victims' perceptions in Beijiang, Guangdong, China, Area 33, 190-201, 2001.

Wu, C. H., Huang, G. R., Yu, H. J., Chen, Z. Q., and Ma, J. G.: Spatial and temporal distributions of trends in climate extremes of the Feilaixia catchment in the upstream area of the Beijiang River Basin, South China, Int. J. Climatol., 34, 31613178, doi:10.1002/joc.3900, 2014a.
Wu, C., Huang, G., Yu, H., Chen, Z., and Ma, J.: Impact of climate change on reservoir flood control in the upstream area of the Beijiang River Basin, South China, J. Hydrometeor., 15, 2203-2218, doi:10.1175/JHM-D-13-0181.1, 2014b.

Wu, Z. Y., Lu, G. H., Liu, Z. Y., Wang, J. X., and Xiao, H.: Trends of Extreme Flood Events in the Pearl River Basin during 19512010, Adv. Climate Change Res., 4, 110-116, 2013.

Xiao, H., Lu, G. H., Wu, Z. Y., and Liu Z. Y.: Flood response to climate change in the Pearl River basin for the next three decades, J. Hydraul. Eng., 12, 1409-1419, 2013 (in Chinese).

Xu, Y. P., Zhang, X., Ran, Q., and Tian, Y.: Impact of climate change on hydrology of upper reaches of Qiantang River Basin, East China, J. Hydrol., 483, 51-60, 2013. 